\title{
Pembuatan Batik Alam Berbahan Tumbuhan Sekitar Rumah
}

\section{Natural Batik Production Made From Home Plants}

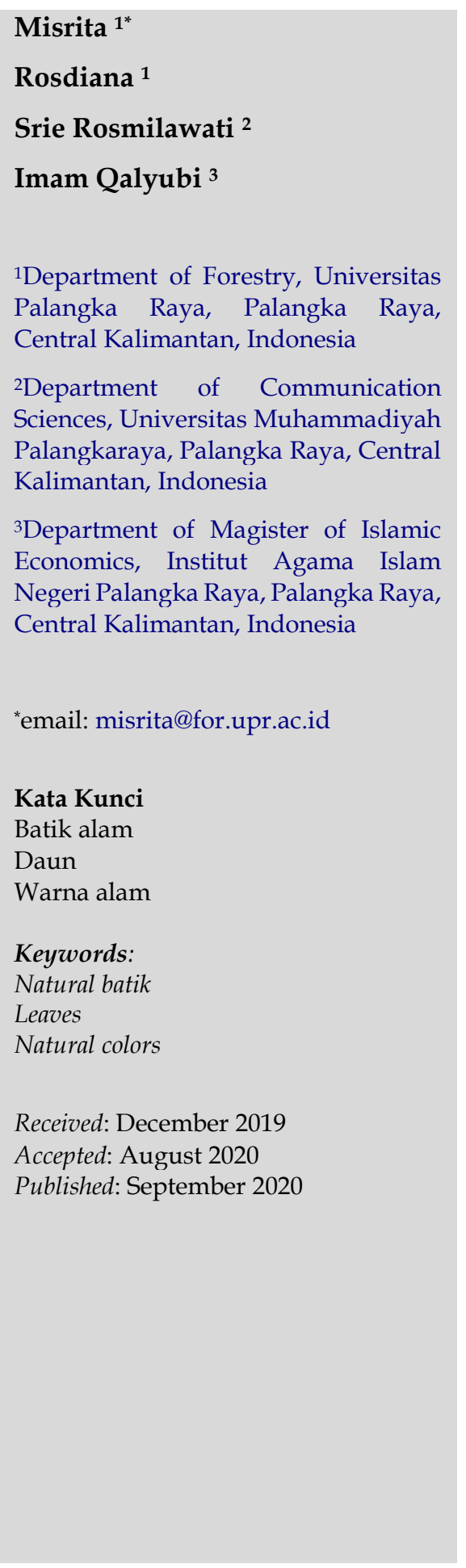

\begin{abstract}
Abstrak
Batik merupakan salah satu seni budaya Indonesia yang sudah menyatu dengan masyarakat Indonesia sejak beberapa abad lalu. Namun selama ini batik yang dihasilkan masih menggunakan motif dan pewarnaan sintetis yang menyumbang pencemaran lingkungan maka minat masyarakat pada batik mulai berkurang, sehingga perlu dicari terobosan baru dalam motif dan pewarnaan batik yang lebih ramah lingkungan dengan menggunakan pewarna alami. Pewarna alami untuk batik salah satunya adalah menggunakan daun tumbuhan di sekitar rumah biasa disebut juga dengan ecoprint merupakan kegiatan melakukan penyusunan daun-daun dengan pola-pola tertentu pada sehelai kain kaos, yang menghasilkan pola motif dan warna yang didapatkan dari daun-daun tersebut. Mitra sasaran yang dilibatkan dalam kegiatan pengabdian kepada masyarakat ini adalah kelompok usaha wanita yang ada di Palangka Raya berada dalam binaan Dinas Koperasi, Usaha Kecil, dan Menengah Kota Palangka Raya yaitu UKM Bawi Dayak Palangka Raya. Hal ini karena batik yang dihasilkan selama ini masih menggunakan motif dan pewarnaan sintetis. Pendampingan yang dilakukan bagi kelompok ini adalah memberikan wawasan pengetahuan dan pengertian tentang pentingnya pewarnaan alami dan berbahayanya pewarna sintetis. Membangun dan mendorong kreativitas dalam membentuk design motif dan warna pada kain melalui pemanfaatan daun yang tumbuh di sekitar rumah. Target luaran berupa produk kain kaos yang menggunakan daun sebagai motif dan pewarna alami. Memperkenalkan batik alam dengan penggunaan sumber daya sekitar.
\end{abstract}

\begin{abstract}
Batik is one of Indonesia's cultural arts, which has been integrated with Indonesian people since several centuries ago. However, so far, the batik produced still uses synthetic motifs and coloring, which can contribute to environmental pollution. Hence, people's interest in batik starts to diminish, so it is necessary to find breakthroughs in batik motifs and coloring, which are more environmentally friendly by using natural dyes. One of the natural dyes for batik is to use plant leaves that grow around the house, also called eco print, which is the activity of making leaves with specific patterns on a t-shirt, which produces motifs and colors obtained from the leaves. The target partners involved in community service activities are women's business groups in Palangka Raya, which are under the auspices of the Palangka Raya City Cooperative, Small and Medium Enterprises Agency, namely UKM Bawi Dayak Palangka Raya. This is because the batik produced so far still uses synthetic motifs and coloring. Assistance carried out for this group is to provide insight into knowledge and understanding of the importance of natural coloring and the danger of synthetic dyes. Build and encourage creativity informing design motifs and colors on fabric through the use of leaves that grow around the house. Outcome targets are t-shirt products that use leaves as motifs and natural dyes - introducing natural batik with the use of natural resources around.
\end{abstract}




\section{PENDAHULUAN}

Industri benang bintik atau batik di Kota Palangka Raya cukup potensial untuk dikembangkan. Hal ini dilakukan untuk menunjang perkembangan industri pariwisata daerah. Dengan jumlah penduduk yang cukup besar yaitu sebanyak sebanyak 258.156 orang, angkatan kerja tahun 2017 dengan rentang usia 25-29 tahun sebesar 25.588 orang (Badan Perencanaan Pembangunan Daerah Palangka Raya, 2018).

Kota Palangka Raya memiliki sentra kawasan industri Temanggung Tilung sebagai prioritas utama bidang industri dalam rangka mewujudkan Palangka Raya sebagai sentra industri kreatif bercirikan kekhasan daerah. Beragam jenis industri kecil di Kota Palangka Raya antara lain industri kerajinan benang bintik, industri meubel Temanggung Tilung, industri kerajinan anyaman rotan, industri kerajinan batu permata, industri kerajinan getah nyatu, industri kerajinan furnitur dan ukiran kayu serta industri pangan (Nurbudiyani et al., 2019). Jumlah Usaha Mikro, Kecil dan Menengah (UMKM) yang terdata pada Dinas Koperasi dan UKM Kota Palangka Raya pada tahun 2016 dari 3.087 usaha yang sudah memiliki IUMK, sebanyak 2.207 masuk dalam kualifikasi usaha mikro, 525 adalah usaha kecil dan 355 dalam usaha menengah (Pemerintah Kota Palangka Raya, 2018).

Kondisi tersebut sejalan dengan visi kota Palangka Raya Tahun 2018 yakni “Terwujudnya Kota Palangka Raya yang Maju, Rukun, dan Sejahtera Untuk Semua" dan Misi "Mewujudkan kesejahteraan masyarakat kota Palangka Raya Smart Economy (ekonomi cerdas) meliputi pengembangan industri, usaha kecil dan menengah, pariwisata, dan perbankan". Maka untuk mewujudkan misi tersebut semua pihak harus saling bersinergis, terutama mengembangkan usaha kecil dengan melibatkan kelompok-kelompok UMKM yang sudah ada (Anggraeni et al., 2013).
Persoalan yang dihadapi Pemerintah Kota adalah kemampuan untuk membina dan pendampingan bagi semua UMKM yang ada dan tersebar di beberapa tempat, untuk itulah keterlibatan Perguruan Tinggi seperti Universitas Palangka Raya (UPR) sangat dibutuhkan sekaligus dalam melaksanakan Tri Dharma Perguruan Tinggi (Hartono \& Hartomo, 2014). Hal ini sejalan dengan poin sasaran renstra UPR 2015-2019 menjadi universitas pembelajaran bermutu yang sehat organisasi berupa program peningkatan kualitas dan kompetensi dosen dalam pelaksanaan Tridharma Perguruan Tinggi tahun 2015-2019.

Keterampilan yang dimiliki dan ditekuni oleh masyarakat umumnya diperoleh dari pelatihan secara formal maupun secara informal (pelatihan yang dibina oleh pihak Kecamatan, Dinas Koperasi, Dinas Perdagangan dan Perindustrian) ataupun secara otodidak, seperti memanfaatkan hasil hutan bukan kayu berupa rotan, kulit kayu, daun, serat ataupun bagianbagian tertentu dari tumbuhan ataupun bahan lainnya (Andriani \& Widowati, 2017). Masyarakat Dayak yang merupakan salah satu suku besar di Kalimantan Tengah lebih banyak menggantungkan hidup mereka pada kekayaan alam yang ada di lingkungannya. Hasil interaksi dengan lingkungan ini memunculkan aneka kebudayaan yang menggambarkan kearifan lokal salah satunya adalah pemanfaatan hasil hutan bukan kayu sebagai sumber penghidupan mereka (Sugiyanto, 2011). Salah satu hasil hutan bukan kayu itu adalah daun tanaman yang tumbuh di sekitar rumah yang dapat dimanfaatkan oleh masyarakat. Namun daun-daun tanaman ini masih belum maksimal dipergunakan karena selama ini masih dimanfaatkan sebagai obat tradisional. Pemanfaatan daun tanaman yang tumbuh di sekitar rumah untuk motif dan warna alami batik tekstil belum dikembangkan (Nono et al., 2017). 
Menurut Mukhlis (2011), pewarna alami selain aman dan ramah lingkungan juga sangat disukai konsumen karena mempunyai warna yang indah dan khas serta tidak bisa ditiru oleh pewarna sintetis. Pewarna alami ini bisa didapatkan pada bagian-bagian tumbuhan seperti kulit, batang, akar, bunga, buah, dan daun. Menurut Marnoto et al. (2012), beberapa tanaman yang dapat digunakan sebagai bahan pewarna alami adalah alpukat, cabe, cengkeh, jambu, kunyit, kayu manis, melinjo, mangga, delima, mahoni, secang dan lain-lain. Bahan yang digunakan sebagai bahan pewarna alami adalah berupa "Pigmen" yang dimiliki atau dikandung dari bagian-bagian tumbuhan tersebut. Beberapa pigmen alami tersebut adalah khlorofil, karotenoid, tannin dan antosinin (Chintya \& Utami, 2017).

Batik alam adalah suatu kegiatan melakukan penyusunan daun-daun dengan pola-pola tertentu pada sehelai kain. Setelah melalui beberapa tahapan proses maka akan dihasilkan batik dengan desain dan warna yang didapatkan dari daun-daun yang telah disusun sebelumnya (Marzuqi et al., 2015). Poin lebih yang ditawarkan dalam teknik ini adalah pewarna dari bahan alami yang dihasilkan adalah warna-warna yang unik dan sangat berbeda dari pewarna sintetis. Keutamaannya adalah menghasilkan produk yang ramah lingkungan, sehingga mendukung program pemerintah baik lokal, regional, nasional bahkan internasional tentang produk ramah lingkungan (Sunyoto et al., 2020).

Permasalahan yang ada pada kelompok-kelompok yang menjadi mitra adalah masih terbatasnya jenis produk yang dihasilkan. Jenis-jenis produk kalah bersaing dengan produk yang sejenis di pasaran. Keadaan ini membuat kelompok menjadi lambat untuk berkembang dan berimbas pada rendahnya penghasilan (Yansahrita, 2018).
Produk tekstil yang dihasilkan dengan motif dan warna alami yang memanfaatkan ragam daun tanaman yang tumbuh di sekitar rumah khas Kalimantan Tengah ini tidak hanya menambah nilai estetika dari produk namun juga akan menambah nilai ekonomi dari produk yang dihasilkan. Adapun kelompok pengrajin batik UKM Bawi Dayak yang selama ini masih memproduksi batik dengan pewarna sintetis dapat menggunakan daun tanaman yang tumbuh di sekitar rumah ini untuk meningkatkan nilai jual dan menghasilkan produk yang lebih menarik, dapat diaplikasikan pada beberapa jenis kain, dan dapat dipergunakan dalam berbagai kesempatan baik formal maupun informal. Berbagai macam kreativitas dan inovasi dapat dilakukan untuk menghasilkan suatu produk, seperti baju kaos dengan warna dan motif daun khas tanaman yang tumbuh di sekitar rumah Kalimantan Tengah. Keterlibatan Mahasiswa dalam kegiatan Pengabdian Pada Masyarakat ini setidaknya membuka wawasan dan penerapan serta aplikasi tentang Kewirausahaan sehingga jiwa usaha terbentuk.

\section{METODOLOGI}

Metode pelaksanaan yang dilakukan pada kegiatan Pelatihan dan Pendampingan Pembuatan Batik Alam Berbahan Tumbuhan Sekitar Rumah Pada Kelompok Perajin UKM Bawi Dayak Palangka Raya ini bertujuan untuk menjelaskan langkah-langkah kegiatan yang dilakukan atau solusi yang dilakukan untuk mengatasi masalah yang ada pada kelompok usaha wanita "Bawi Dayak".

Metode yang diterapkan dalam kegiatan ini adalah pelatihan dan praktek langsung. Dalam pelatihan ini diberikan beberapa kegiatan yang meliputi penyajian materi, dan praktik pewarnaan alam pada replika daundaun ke dalam bahan-bahan tekstil kepada para peserta pelatihan. Jangka waktu pelaksanaan selama empat 
bulan, kegiatan setiap bulan mencakup koordinasi, sosialisasi dan pembekalan, pelatihan, pendampingan, diskusi dan monitoring evaluasi.

\section{HASIL DAN PEMBAHASAN}

Beberapa kegiatan yang telah dilakukan dalam program PKM ini meliputi persiapan dan sosialisasi, pelaksanaan kegiatan (penyajian materi, praktek membatik alam), pendampingan serta monitoring dan evaluasi. Berikut penjelasan dan dokumentasi kegiatan tersebut:

\section{Persiapan}

Tahap ini dilakukan sebelum pelaksanaan PKM, yaitu melakukan koordinasi internal tim pelaksana, membuat rencana pelaksanaan berupa jadwal dan tempat pelaksanaan. Pembuatan instrumen PKM, seperti lembar presensi, lembar kerja, penyusunan modul pelatihan, dan persiapan alat dan bahan, serta persiapan dokumentasi.

\section{Pelaksanaan kegiatan}

Pelaksanaan kegiatan dilakukan selama dua hari, masing-masing untuk kelompok Bawi Dayak pada tanggal 14 Oktober 2019 di jalan Adonis Samad Kompleks Damai Sejahtera No 21 Blok A2 Palangka Raya. Kegiatan yang dilakukan pada masing masing kelompok adalah sama yaitu Penyajian Materi dan Praktek pembuatan Batik Alam dengan teknik Pounding. Penyajian materi dilakukan dengan memberikan modul kepada masing-masing peserta sebanyak 5 orang anggota kelompok mitra. Modul berisi tentang pemahaman teknik pembuatan batik alam dengan teknik pounding. Bahan dan alat yang diperlukan serta bagaimana tekhnik pengerjaannya. Sebelum pelaksanaan pelatihan bahan kain kaos perlu dilakukan pemordanan seperti Gambar 1 dan 2 berikut.

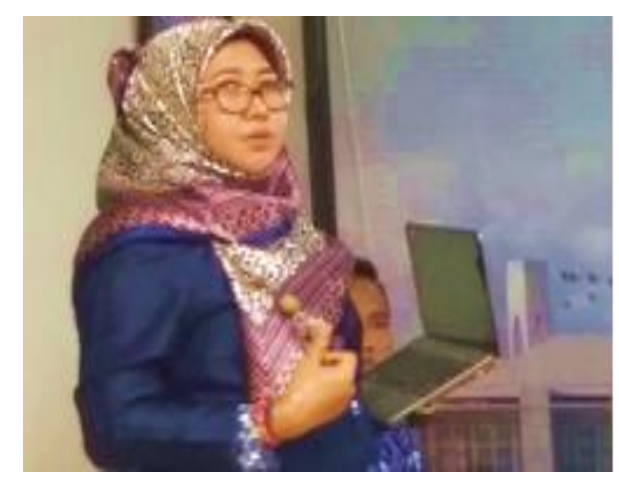

Gambar 1. Penyampaian materi oleh tim pelaksana

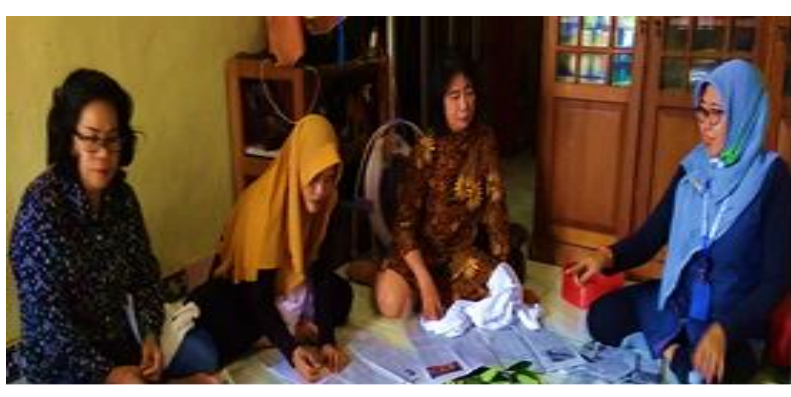

Gambar 2. Presentasi Materi batik alam

Sebelum pelaksanaan praktek dilakukan pembagian bahan dan alat kepada kelompok mitra. Urut-urutan kegiatan dilakukan sebagai berikut:

1. Teknik perendaman daun

Sediakan air dan bahan tunjung dengan perbandingan $1 \mathrm{~L}$ air : $30 \mathrm{~g}$ tunjung, kemudian larutkan bahan tersebut. Selanjutnya masukkan bahan daun sampai tenggelam rendam beberapa saat setelah itu ditiriskan di atas koran. Dokumentasi proses disajikan pada Gambar 3 sampai 5 .

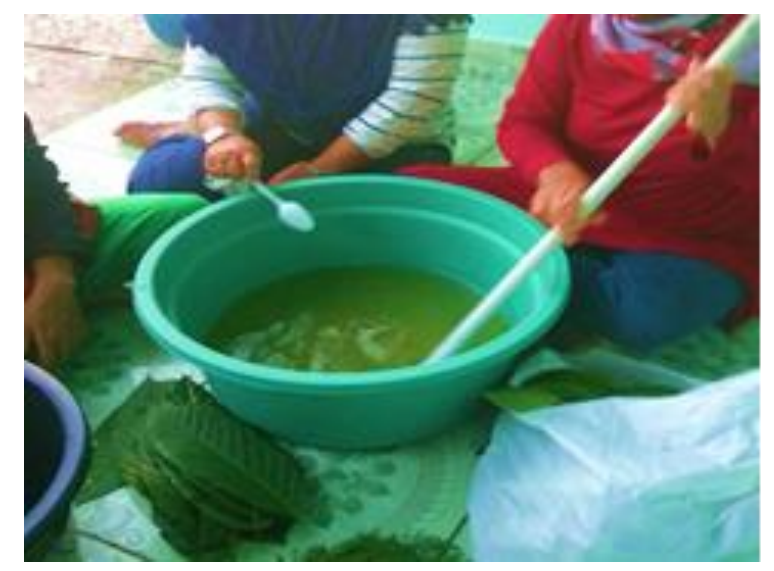

Gambar 3. Pencampuran air dan Tunjung 


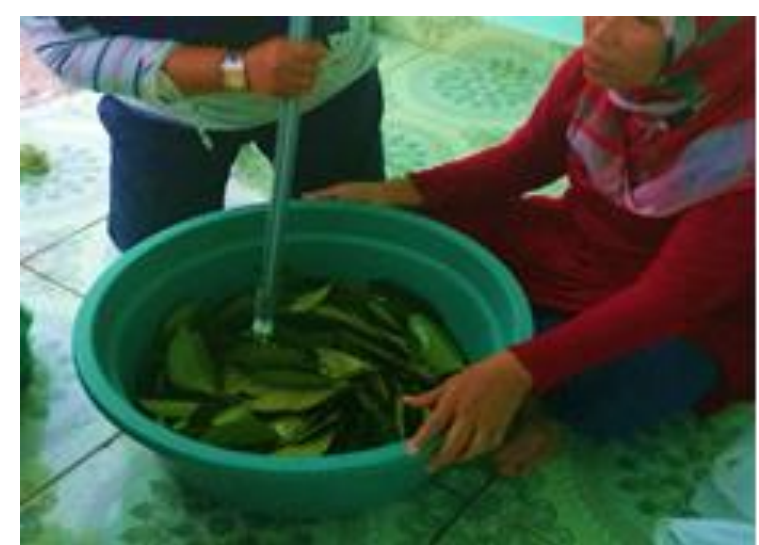

Gambar 4. Pengadukan

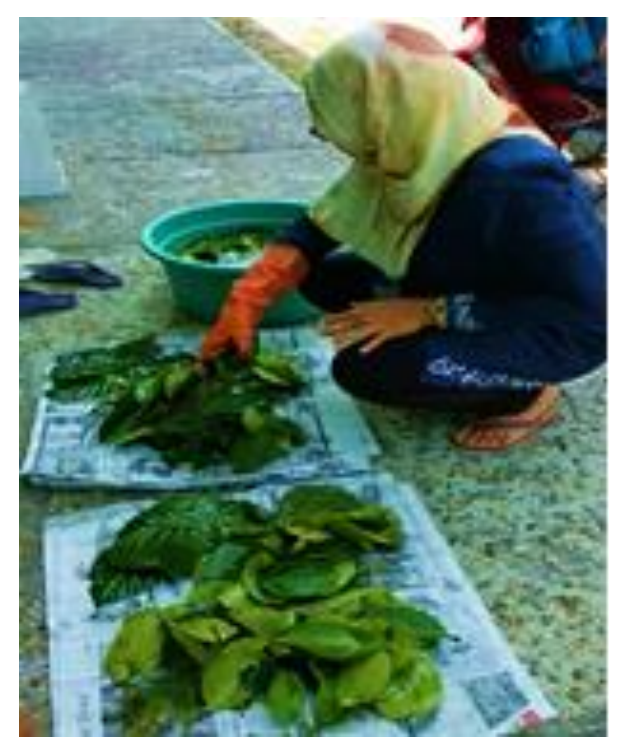

Gambar 5. Penirisan daun

2. Penyiapan Kain kaos yang akan dibatik alam

Letakkan plastik dalam kaos, kemudian tutupi plastik tersebut dengan kertas tisu makan seperti ditunjukkan pada Gambar 6.

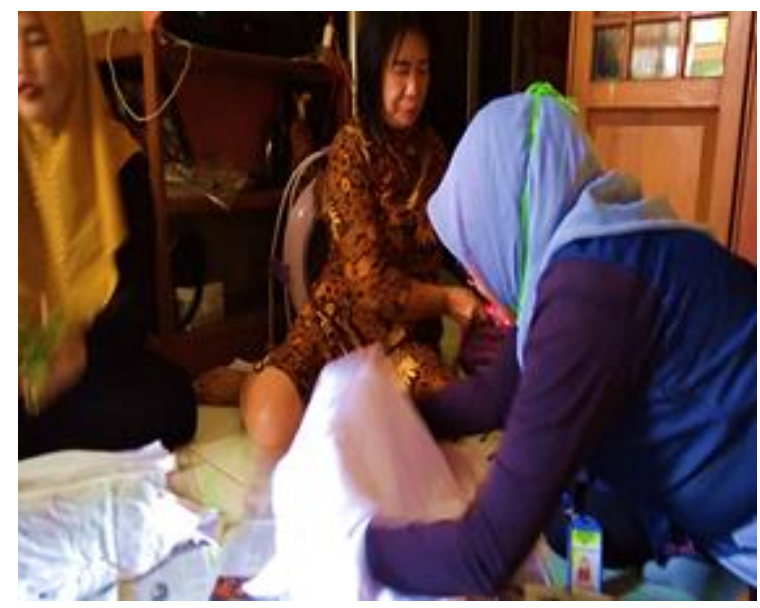

Gambar 6. Penyusunan plastik-tisu pada kaos
3. Pembuatan desain motif daun di atas kain Letakkan daun di atas potongan bahan kain secara acak tergantung motif yang ingin diciptakan sebagaimana ditunjukkan pada Gambar 7.

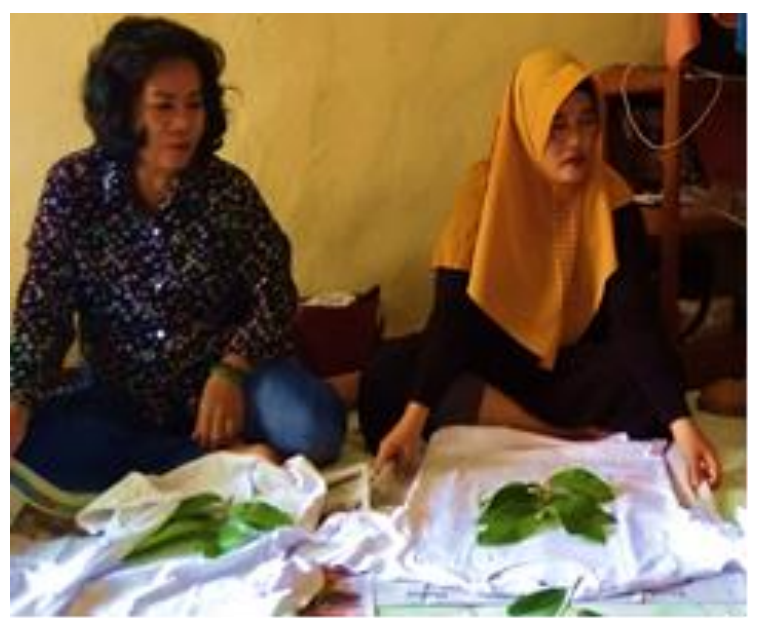

Gambar 7. Pembuatan desain motif daun di atas kain

4. Teknik pounding/memukul daun dengan palu Agar warna dan motif daun yang ditempelkan pada kain kaos dapat maksimal memberikan warna dan motif pada kain maka daun yang sudah disusun dipounding/dipukul dengan palu yang terlebih dahulu ditutup dengan plastik agar daunnya tidak hancur. Dokumentasi proses disajikan pada Gambar 8 dan 9.

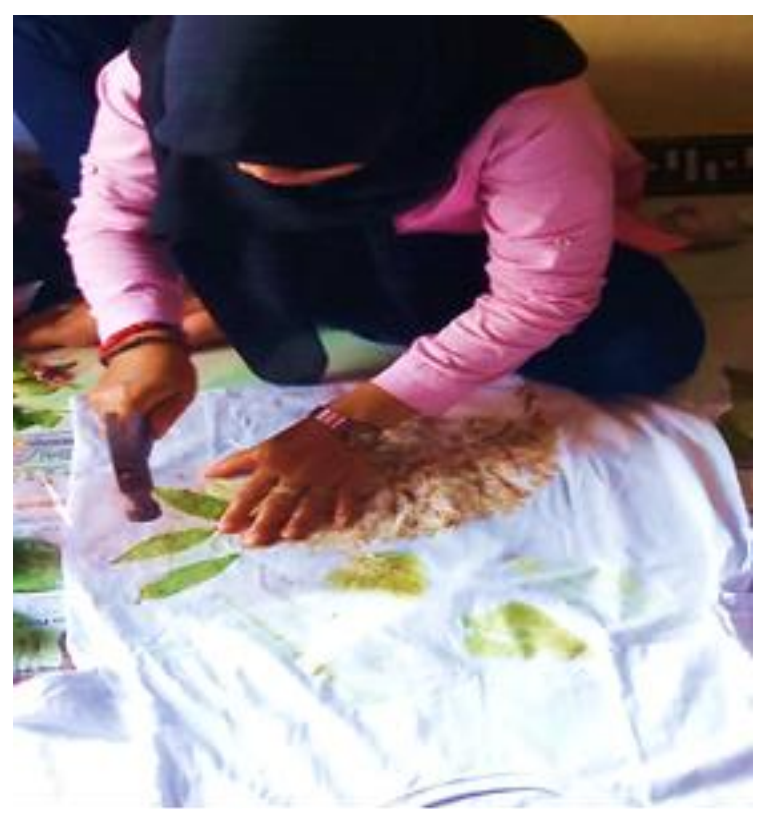

Gambar 8. Teknik pounding daun 


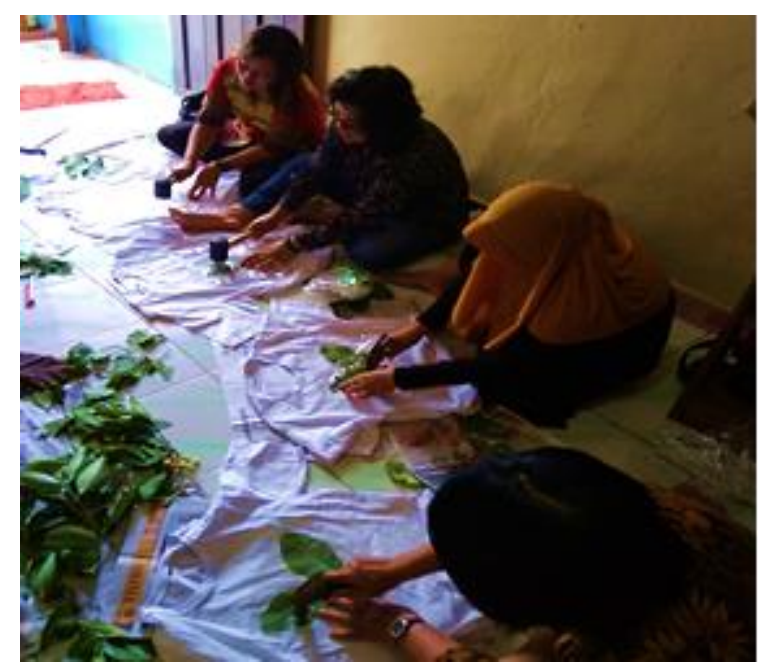

Gambar 9. Para peserta melakukan pounding daun dengan palu

5. Teknik pengeringan kain kaos

Letakkan kain kaos batik alam dengan cara dianginanginkan sebaiknya tidak terkena matahari langsung. Simpan selama minimal tiga hari, setelah itu baru dilakukan fiksasi untuk membuat motif dan warna lebih menempel pada bahan kaos. Proses Pengeringan disajikan pada Gambar 10.

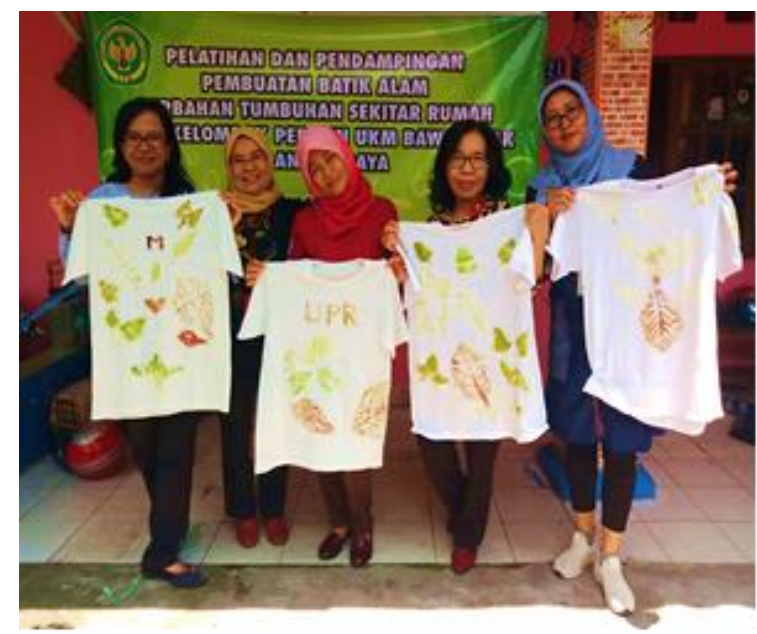

Gambar 10. Batik alam kain kaos dianginanginkan

6. Hasil akhir Batik alam bahan kaos

Setelah dilakukan fiksasi maka kaos batik alam dapat dikenakan untuk bergaya, sebagaimana ditunjukkan pada Gambar 11.

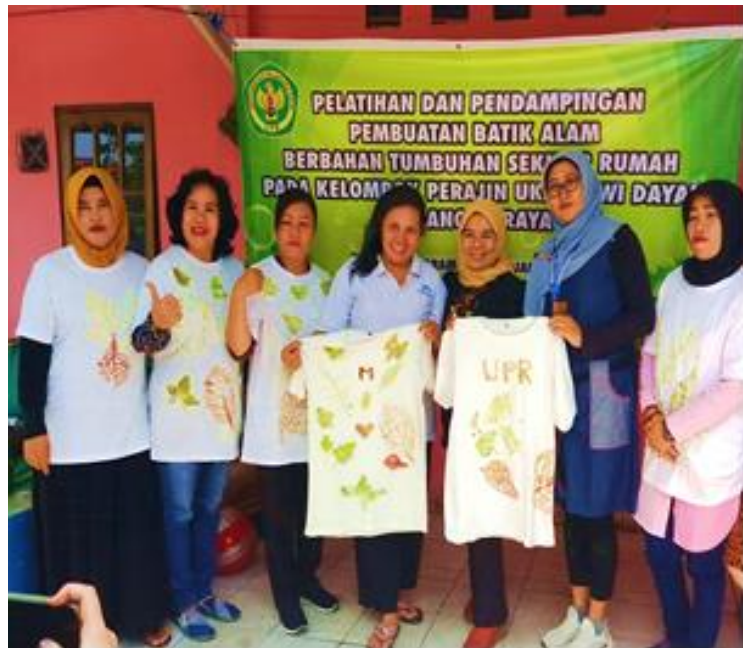

Gambar 11. Hasil akhir batik alam kaos

\section{Monitoring dan evaluasi}

Setelah pelaksanaan pelatihan, selanjutnya dilakukan monitoring dan evaluasi sebanyak lima kali kepada masing masing kelompok mitra. Topik yang dibicarakan pada saat pelaksanaan monitoring dan evaluasi adalah pihak mitra menyampaikan beberapa hal antara lain keinginan untuk melanjutkan kegiatan ini menjadi suatu usaha. Pihak mitra juga menyatakan bahwa mereka sudah mendapatkan pesanan dari beberapa teman di sekitarnya. Namun kendala yang dihadapi berupa sulitnya mendapatkan bahan penunjang untuk bahan perendaman yang tidak ada dijual di kota Palangka Raya dan sekitarnya.

Disisi lain, mereka juga terhambat kurangnya permodalan. Tanggapan yang disampaikan oleh pihak tim PKM terhadap keinginan para mitra untuk melanjutkan usaha ini adalah akan mendukung penuh dan siap untuk selalu mendampingi dan menjelaskan apa saja yang belum mereka kuasai secara teknis. Untuk bahan penunjang tim PKM juga siap membantu untuk pemesanan. Untuk permodalan pihak PKM mengusahakan untuk mengarahkan kepada instansi yang berwenang. 


\section{KESIMPULAN}

Berdasarkan hasil dan serangkaian kegiatan yang sudah dilakukan seperti tersebut di atas maka dapat diambil kesimpulan bahwa semua tahapan kegiatan pelatihan mulai dari penjelasan materi dipahami dengan baik. Hal ini bisa dibuktikan ketika pelaksanan dapat dilakukan dengan baik oleh seluruh peserta dengan hasil yang cukup memuaskan. Seluruh peserta menyatakan diri bahwa mereka sangat antusias dalam mengikuti pelatihan tersebut dan masing-masing berkeinginan mencoba sendiri di kemudian hari. Diperlukan dukungan dari pihak instansi terkait untuk pengembangan lebih lanjut kegiatan ini, sehingga bisa menjadi salah satu pilihan untuk meningkatkan pendapatan mitra khususnya. Lebih luas lagi dapat mensejahterakan masyarakat yang bergerak di bidang usaha rumah tangga.

\section{UCAPAN TERIMA KASIH}

Terima kasih kami sampaikan kepada Direktur Pascasarjana Universitas Palangka Raya, Kementrian Riset, Teknologi dan Pendidikan Tinggi yang telah mendanai pengabdian masyarakat ini melalui program kemitraan wilayah sesuai dengan kontrak Program Pengabdian kepada Masyarakat Tahun Anggaran 2019.

\section{REFERENSI}

Andriani, I., Widowati, N. 2017. Pengembangan Industri Kecil dan Menengah di Kota Semarang (Studi Kasus pada Dinas Perindustrian dan Perdagangan Kota Semarang di Bidang Perindustrian). Journal of Public Policy and Management Review. 6(2):1-15. https://doi.org/10.14710/jppmr.v6i2.16215

Anggraeni, F.D., Hardjanto, I., Hayat, A. 2013. Pengembangan Usaha Mikro, Kecil Dan Menengah (UMKM) Melalui Fasilitasi Pihak Eksternal Dan Potensi Internal (Studi Kasus Pada Kelompok Usaha "Emping Jagung" Di Kelurahan Pandanwangi Kecamatan
Blimbing Kota Malang). JAP (Jurnal Administrasi Publik). 1(6):1286-1295.

Badan Perencanaan Pembangunan Daerah Palangka Raya. 2018. Profil Kota Palangka Raya Tahun 2017. Palangka Raya: Badan Perencanaan Pembangunan Daerah Palangka Raya.

Chintya, N., Utami, B. 2017. Ekstraksi Tannin dari Daun Sirsak (Annona muricata L.) sebagai Pewarna Alami Tekstil. JC-T (Journal Cis-Trans) : Jurnal Kimia dan Terapannya. 1(1):22-29. http://dx.doi.org/10.17977/um026v1i12017p 022

Hartono, Hartomo, D.D. 2014. Faktor-Faktor Yang Mempengaruhi Perkembangan UMKM Di Surakarta. Jurnal Bisnis Dan Manajemen. 14(1):15-30. https://doi.org/10.20961/jbm.v14i1.2678

Marnoto, T., Haryono, G., Gustinah, D., Putra, F.A. 2012. Ekstraksi Tannin Sebagai Bahan Pewarna Alami Dari Tanaman Putrimalu (Mimosa Pudica) Menggunakan Pelarut Organik. Jurnal Reaktor. 14(1):39-45. https://doi.org/10.14710/reaktor.14.1.39-45

Marzuqi, A., Fianto, A.Y.A., Hidayat, W. 2015. Penciptaan Motif Batik Sebagai Ikon Kabupaten Lumajang. Art Nouveau. 4(1):1-12.

Mukhlis, M. 2011. Ekstraksi Zat Warna Alami Dari Kulit Batang Jamblang (Syzygium Cumini) Sebagai Bahan Dasar Pewarna Tekstil. Biologi Edukasi: Jurnal Ilmiah Pendidikan Biologi. 3(1):35-42.

Nono, Diba, F., Fahrizal, M. 2017. Pemanfaatan Hasil Hutan Bukan Kayu Oleh Masyarakat Di Desa Labian Ira'ang Dan Desa Datah Diaan Di Kabupaten Kapuas Hulu. Jurnal Hutan Lestari. 5(1):76-87.

Nurbudiyani, I., Sonedi, S., Suyati, E.S., Pratama, M.R.F. 2019. Development of Micro, Small and Medium Enterprises Rattan Woven Crafts in Central Kalimantan, Indonesia. Anterior Jurnal. 18(2):132-142.

https://doi.org/10.33084/anterior.v18i2.533

Pemerintah Kota Palangka Raya. 2018. Potensi DaerahIndustri Kecil dan Menengah. Palangka Raya: Pemerintah Kota Palangka Raya. 
Sugiyanto, S. 2011. Kehidupan Sosial Budaya Etnis Dayak Iban Di Badau. Sosio Informa. 16(2):133144. https://doi.org/10.33007/inf.v16i2.960

Sunyoto, M.B., Banindro, B.S., Yulianto, Y.H. 2020. Perancangan Fotografi Fashion Pewarna Alami Dari Ampas Kopi. Jurnal DKV Adiwarna. 1(16):1-9.

Yansahrita, Y. 2018. Penerapan Strategi Bisnis Untuk Kelangsungan Hidup Produk Usaha Kecil Dan Menengah Di Zaman Digital Atau Zaman "Now". Aktual. 16(1):39-46. https://doi.org/10.47232/aktual.v16i1.5 